\title{
Contribution of family risk, emergent literacy and environmental protective factors in children's reading difficulties at the end of second-grade
}

\author{
Zahra Esmaeeli ${ }^{1,2}\left([) \cdot\right.$ Fiona E. Kyle $^{3}\left([) \cdot\right.$ Kjersti Lundetræ $^{1}(\mathbb{C}$
}

Published online: 18 May 2019

(c) The Author(s) 2019

\begin{abstract}
It is well established that emergent literacy is a strong predictor of later reading difficulties, and that the home literacy environment plays an important role in the development of children's preschool emergent literacy and oral language. Furthermore, reading difficulties runs in families and children with a family risk of reading difficulties tend to show delays in emergent literacy and might experience a less advantageous home literacy environment. This study examined whether family risk predicts children's second-grade reading difficulties in a multifactorial model including both emergent literacy and environmental protective factors such as home literacy environment and parental level of education. Children were assessed for emergent literacy at the beginning of first grade, and were identified as having reading difficulties at the end of second grade if they performed below the national threshold in at least three of the subtests in reading and spelling. The multifactorial model suggested that children with family risk showed reading difficulties that could not be explained in terms of individual differences in emergent literacy, gender, interest in literacy, years in kindergarten, home literacy environment or parental education level. These findings highlight the advantages of using multifactorial models of reading difficulties that encompass different domains of genetic, cognitive-based and environmental factors. In sum, not only did we find family risk is associated with children's literacy outcomes after 2 years of formal reading instruction, but we also identified possible modifiable factors that may benefit from interventions and lessen the likelihood of developing reading difficulties.
\end{abstract}

Keywords Reading difficulties · Family risk - Multifactorial prediction model · Emergent literacy $\cdot$ Home literacy environment

Zahra Esmaeeli

Zahra.esmaeeli@uis.no

Extended author information available on the last page of the article 


\section{Introduction}

Literacy skills provide a crucial foundation for children's later success in educational, professional and everyday settings. While most children learn to read and write successfully, some experience reading and writing difficulties. The prevalence of reading difficulties across the domains of reading, spelling and reading comprehension is 5-15\% among school-age children across different languages and cultures (American Psychiatric Association, 2013). Reading difficulties (RD), or dyslexia, has many definitions and different criteria. In general RD refers to unexpected impairments in the process of reading and spelling acquisition which are not due to extraneous factors like sensory intelligence, acuity deficits, socioeconomic disadvantage, and similar factors (Vellutino, Fletcher, Snowling, \& Scanlon, 2004). There is accumulating evidence that RD can be prevented in many children through early intervention (Fletcher, Lyon, Fuchs, \& Barnes, 2007; Lovett et al., 2017; Torgesen, 2002), and this means that early prediction of RD or identification of at-risk children is of both theoretical and practical interest.

Predictors of RD have been extensively investigated in young children in order to identify which variables may identify at-risk children prior to the onset of formal instruction. Predictors have been identified from different domains including cognitive, biological and environmental factors. Cognitive-based factors typically include individual differences in emergent literacy and oral language skills; biological-based factors include a genetic cause or a history of RD within the family known as family risk (FR); and environmental factors include the home literacy environment (HLE) and parental level of education. The range of predictive factors has resulted in both single and multiple deficit models of RD (Bishop \& League, 2006; Carroll, Mundy, \& Cunningham, 2014; Catts, Nielsen, Bridges, Liu, \& Bontempo, 2015; McCardle, Scarborough, \& Catts, 2001; Puolakanaho et al., 2007), in which factors from one or more of these domains have been controlled.

\section{Emergent literacy}

The term emergent literacy is used to describe a broad range of pre-literacy skills, knowledge, and attitudes that children acquire prior to formal schooling, and which provides a foundation for later literacy development (Whitehurst \& Lonigan, 2001). Emergent literacy such as letter knowledge, phonemic awareness, vocabulary and other cognitive processing skills [e.g., rapid automatized naming (RAN) and short term memory] have been found to be predictive of children's later RD (Elbro, Borstrøm, \& Petersen, 1998; Lonigan, Schatschneider, \& Westberg, 2008). This prediction model forms the basis of the widely-accepted cognitive deficit models that have mainly focused on early symptoms in order to identify and remediate reading problems as early as possible (Pennington, 2006). The dominant cognitive deficit model of $\mathrm{RD}$ is the phonological deficit theory/ 
model, which postulates a core deficit in phonological processing as being causally related to RD (Hulme \& Snowling, 2013; Pennington, 2006). Double deficit models that consist of deficits in both RAN and phonological processing skills have guided other studies (Cardoso-Martins \& Pennington, 2004; Catts et al., 2015; Pennington, Cardoso-Martins, Green, \& Lefly, 2001; Torppa et al., 2013). Moreover, cognitive multiple deficit or multivariate models have been hypothesized comprising of phonological skills and RAN in addition to short term memory (Bishop \& League, 2006; McGrath et al., 2011) or oral language skills (Catts, McIlraith, Bridges, \& Nielsen, 2017; McCardle et al., 2001; McGrath et al., 2011; Pennington et al., 2012).

\section{Family risk and multiple cognitive prediction model}

In line with the multiple cognitive deficit models, research on family risk (FR) of RD has shown that having a history of RD within the family, can put the child at high risk for RD. A meta-analysis of previous studies of FR indicates that approximately 29-66\% of children with FR (FR children) will develop RD (Snowling \& Melby-Lervåg, 2016). This meta-analysis also indicates that FR children universally develop emergent literacy more slowly than children without FR (Not-FR children), which in turn puts them at greater risk for RD. In addition, a large body of FR studies have reported that despite the fact that FR children have poorer emergent literacy, the pattern of prediction for later literacy outcomes are similar in FR and NotFR children (Aro et al., 2009; Cardoso-Martins \& Pennington, 2004; Hulme, Nash, Gooch, Lervåg, \& Snowling, 2015; Pennington \& Lefly, 2001; Torppa, Eklund, van Bergen, \& Lyytinen, 2011; Torppa, Lyytinen, Erskine, Eklund, \& Lyytinen, 2010; Torppa, Poikkeus, Laakso, Eklund, \& Lyytinen, 2006; Torppa et al., 2007). However, data are limited on whether FR is a unique predictor of RD over and above emergent literacy and environmental factors such as parents' educational level and the HLE.

Elbro et al. (1998) found that letter naming, preschool phoneme identification, and phonological representations were statistically significant predictors of RD at the beginning of Grade 2, while FR was not. In contrast, Puolakanaho et al. (2007), in a multiple cognitive model, found that FR, preschool letter knowledge, phonemic awareness and RAN were significant predictors of RD at the beginning of Grade 2. In another study, Carroll et al. (2014) investigated the roles of FR, emergent literacy and oral language in predicting children's literacy outcomes. Their findings support those of Puolakanaho et al. (2007), suggesting that FR is a unique predictor of children's literacy even after controlling for speech production, language and phonological processing. Carroll et al. (2014) argued that FR children show additional difficulties in literacy that cannot be fully explained in terms of their language and phonological skills. Furthermore, family risk was found to make an additional contribution in the prediction of Grade 6 reading comprehension after taking into account children's general IQ, verbal IQ, emergent literacy in kindergarten, and reading fluency and accuracy in Grade 2 and 3 (van Viersen et al., 2018). However, none of these studies (Carroll et al., 2014; Puolakanaho et al., 2007; van Viersen 
et al., 2018) included environmental factors such as parental education level or the HLE in their analyses which might have accounted for some of unexplained variance in literacy skills.

\section{Environmental protective factors, family risk, and children's emergent literacy}

It is clear that environmental factors such as the HLE, which refers to the quality and quantity of reading-related activities that parents provide for their children at home, play an important role in the development of children's emergent literacy and oral language skills (Burgess, Hecht, \& Lonigan, 2002; Dilnot, Hamilton, Maughan, \& Snowling, 2017; Hamilton, Hayiou-Thomas, Hulme, \& Snowling, 2016; Sénéchal \& LeFevre, 2002; Torppa et al., 2007; van Bergen, van Zuijen, Bishop, \& de Jong, 2017). The HLE is likely to have long-term and consistent influences on children's later literacy skills either directly or indirectly through emergent literacy skills (Frijters, Barron, \& Brunello, 2000; Sénéchal, 2006). Frijters et al. (2000) discussed that while the HLE was directly related to vocabulary, the relationship between the HLE and later literacy skills was mediated by phonological awareness. Similarly, Sénéchal (2006) reported that HLE directly predicted kindergarten vocabulary but indirectly predicted Grade 4 reading comprehension.

The association between FR and the HLE is less clear and data are limited (Snowling \& Melby-Lervåg, 2016). Some studies report no differences in HLE between FR families and Not-FR families (Elbro et al., 1998; Torppa et al., 2007), whereas others studies report a relatively disadvantageous HLE for FR children compared with Not-FR children (Dilnot et al., 2017; Esmaeeli, Lundetræ, \& Kyle, 2018; Hamilton et al., 2016). Dilnot et al. (2017) found that FR children experienced more environmental adversities than Not-FR children. The environmental factors in their study, consisting of both the HLE and parental education and occupations, predicted children's reading readiness (early word reading, letter knowledge, and phoneme deletion) at school entry. Hamilton et al. (2016) also reported group differences in storybook exposure between FR and Not-FR children. Moreover, Esmaeeli et al. (2018) used parents' self-report of RD to identify FR and Not-FR children, and found a disadvantageous HLE in FR children. In their study, the differences in HLE were even larger when both parents reported RD.

A possible explanation for these inconsistent findings regarding associations between FR and the HLE is parental level of education and/or socioeconomic background (Esmaeeli et al., 2018; Hamilton et al., 2016). In the studies in which the HLE did not differ between FR and Not-FR groups, there were no differences between FR and Not-FR groups in parental education (Torppa et al., 2007) or maternal education (Elbro et al., 1998).

Pennington (2006) argued that RD is a complex developmental disorder that involves the interaction of multiple risk and protective factors, which can be either genetic or environmental. Accordingly, these risk and protective factors influence the development of children's emergent literacy skills which are prerequisites for the development of later literacy skills. FR, as a proxy for genetic 
and environmental factors, may operate as a risk factor that increases the likelihood of RD because it can negatively influence both emergent literacy and later literacy skills (Pennington, 2006; van Bergen, van der Leij, \& de Jong, 2014). Environmental factors, however, can operate as either/or both risk and protective factors. Such multifactorial models can be used to explore the effect of protective environmental factors such as parental educational level and the HLE and risk factors such as FR on children's literacy skills. To the our best of knowledge, no previous FR study has investigated whether FR predicts children's later RD in a multifactorial model which accounts for environmental protective factors such as the HLE, parental level of education in addition to emergent literacy.

\section{Children's interest in literacy}

Children's interest in literacy refers to children acting on their own initiative when it comes to literacy-related activities. In other words, how often children choose themselves to engage in literacy-related activities and how much they enjoy these types of activities (Frijters et al., 2000; Hume, Lonigan, \& McQueen, 2015). Children's interest in literacy has been emphasized as an important factor relating both to emergent literacy and to later literacy skills (Frijters et al., 2000; Hume et al., 2015; Torppa et al., 2007). In addition, children with limited literacy interest may be less willing to be engaged in literacy-related activities (Hume et al., 2015). Given the relationships between children's interest in literacy, their exposure to literacy-related activities (the HLE), their emergent literacy and later literacy skills, this study controlled for children's interest in literacy.

\section{Present study}

The present study uses a multifactorial model of RD to address the following research questions:

1. Does FR status (as a proxy for genetic and environmental factors) identify between group differences in literacy skills at the end of Grade 2? In line with previous FR research we expect that FR children will be more likely to be categorized as having RD at the end of second grade compared with children without FR.

2. Is FR of RD a unique predictor of children's second-grade RD in a multifactorial model that includes emergent literacy and environmental factors at the onset of formal reading instruction? We expect that FR as a proxy for genetic and environmental factors will predict children's RD over and above cognitive-based predictors such as emergent literacy, and other environmental factors such as the HLE and parents' educational level, while controlling for years in kindergarten, gender and children's interest in literacy. 


\section{Method}

\section{Participants and procedure}

For this study, we drew data from an ongoing longitudinal project "On Track" (Lundetræ, Solheim, Schwippert, \& Uppstad, 2017) that has focused on early identification and intervention for RD. Altogether, 1171 6-year-old children joined the project at the beginning of Grade 1, which marks the onset of formal reading in Norway. The parents of $97.7 \%$ of the students gave their consent for participation. In the present study, we only included children from the schools that were randomly assigned to the control condition $(n=260)$. Second-languagespeakers $(n=42)$, children with hearing problems $(n=2)$, and children whose parents did not provide information about RD within the family $(n=6)$, or both parents answered self-report of RD as "I don't know" $(n=2)$ were excluded from the sample. In total, the sample for the present study was 208 children, including 89 boys and 119 girls.

In this study, participating schools offered a welcome meeting for parents before children started first grade. Our research team presented information about the project and about reading difficulties at these meetings and invited parents to take part in the study. Parents received a project pack containing a brochure giving them more information about the project, a parental consent form, and a questionnaire about demographics, the HLE, family risk of RD, the student's language background, and their health. We obtained FR status through this questionnaire, which parents completed at home and sent back to school.

\section{Defining family risk (FR)}

Parents or adult's self-report of RD is a valid, reliable and time-saving tool to screen RD among parents and adults (Leavett, Nash, \& Snowling, 2014; Lefly \& Pennington, 2000; Snowling, Dawes, Nash, \& Hulme, 2012), which has consequently and increasingly been used as a proxy for FR status (Carroll \& Snowling, 2004; Esmaeeli et al., 2018). Snowling et al. (2012) argued that self-report is valid, first, because of its strong relationship with directly assessed literacy skills of respondents (parents) and second, due to the association between the parents' self-reporting of RD and emergent literacy difficulties of their children. The present study uses parents' self-report of RD as an indicator of FR and a proxy for FR status. The information was retrieved from the parents' questionnaire, in which we asked (biological) parents to report about their own reading and writing difficulties, with separate response options for mother and father ('yes', 'no', or 'don't know'). For this study, a positive response to the questions from either the mother or father was sufficient to identify as FR. The term 'Reading and writing difficulties' relates to specific problems with word reading and spelling, and is a familiar term for Norwegian parents as it is frequently used in schools and media. Moreover, this term was discussed at the welcome meeting with parents. 
We used parents' self-report of RD to allocate their children into FR and NotFR groups. The Not-FR group consisted of 161 children from families in which neither parent self-reported RD. Forty-nine children had at least one parent who self-reported RD and formed the FR group. Only three FR children had both parents self-reporting RD. In total, eight families answered 'don't know' to the report of RD for at least one parent. Six of these families were categorized based on the response provided by the other parent because we assumed that this information might not be available for some reason (e.g., single parent family). However, two of these families were excluded because both parents answered 'don't know'. Table 1 presents the background demographics of the sample.

\section{Measures at the beginning of Grade 1}

The early predictors of RD were derived from individual assessments administered at the beginning of first-grade (mean age $=6.21, \mathrm{SD}=0.28$ ). Trained testers individually assessed all students in a quiet place in their local school. The test battery was administered on a digital tablet.

\section{Emergent literacy skills}

Letter knowledge consisted of a 15-item multiple-choice test. Children were asked to listen to a pre-recorded letter sound on the tablet, and respond by pressing on one of four touch-screen letters. Cronbach's $\alpha=.85$.

Phoneme isolation The tablet screen showed a picture, and the examiner pointed to the picture, named it, and asked the child to produce the first sound of that word. The oral response of the child was scored and recorded on the tablet by the examiner. This task contained eight items and presentation was automatically discontinued if a child made two subsequent errors. Cronbach's $\alpha=.92$.

Blending task Children were required to blend a set of separately pronounced phonemes into the corresponding whole word. The test had eight items of increasing difficulty and presentation was automatically discontinued after two subsequent errors. In each item, four pictures appeared on the screen, and the task was prerecorded: "Here you see a picture of /ri/-/rips/-/ris/ and /ring/ (ride, red current, rice, ring, in English). Listen carefully and touch the picture that goes with:/r/-/i/-/s/(presented phoneme-by-phoneme, one per second)". Cronbach's $\alpha=.86$.

For the logistic regression model, a factor score for phonemic awareness was made using Confirmatory Factor Analysis in SPSS (Cronbach's $\alpha=.86$ ).

Rapid automatized naming (RAN) included naming familiar objects presented repeatedly in a random order. The examiner practiced the task with the child and made sure that the child knew the name of each object and understood the procedure of the task. The pictured objects were sun, car, plane, house, fish, and ball, which are all monosyllabic words in Norwegian. There were four rows of five stimuli in each matrix, and two trials. The child was asked to name each item as quickly and accurately as possible from left to right, and top to bottom. Time to complete the task (in seconds) and naming errors were recorded. 


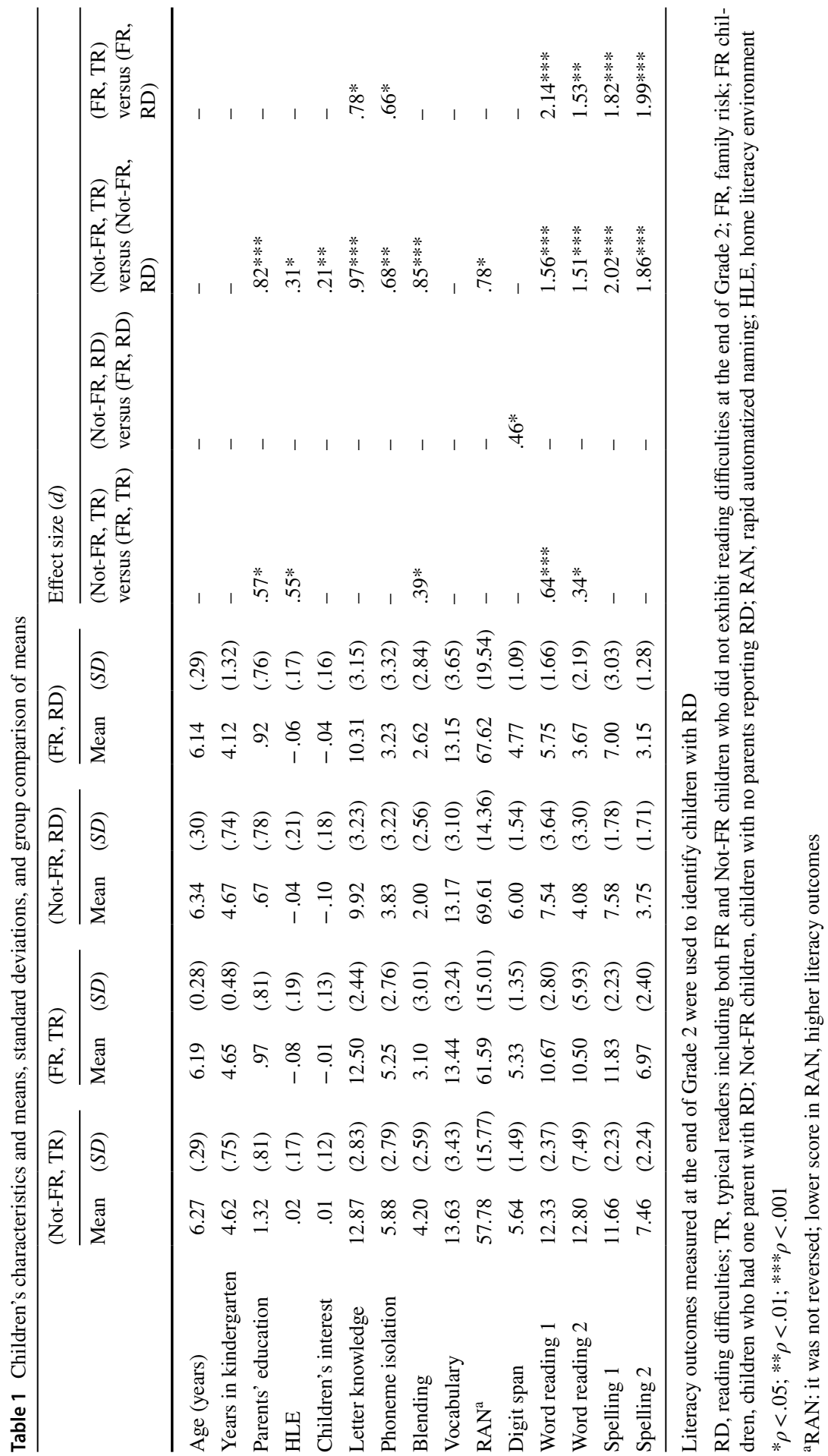


Short-term memory (STM) was measured with Digit Span Forward from the Wechsler Intelligence Scales for Children-III (Wechsler, 1991). The examiner read aloud one digit per second and the child's responses were scored on the tablet.

Vocabulary was tested with an abridged version (20 out of 40 words) of the Norwegian Vocabulary Test (NVT) (Størksen, Ellingsen, Tvedt, \& Idsøe, 2013). A picture appeared on the screen and the child was asked to name it. Cronbach's $\alpha$ for 20 items in the present sample was .83 , which is virtually identical to the 40 items in the standardized sample (Cronbach's $\alpha=.84$ ).

\section{Parents' questionnaire}

Parents answered a questionnaire regarding with their educational level, the HLE and the child's interest in reading.

(a) Parents' educational level was considered at three levels.

High level At least one parent reported having a university/college degree Medium level Neither parent had a university/college degree. At least one reported a high school diploma or equivalent

Low level Both parents reported that they only finished the compulsory primary and secondary school

(b) Child's interest in literacy was assessed through two items including (a) My child often asks to be read to, and (b) My child is interested in letters [1 (completely disagree) to 4 (completely agree)]. (Cronbach's $\alpha=.41$ ).

(c) Home Literacy Environment (HLE).

The measure of HLE was constructed in line with previous research (Dilnot et al., 2017; Esmaeeli et al., 2018; Hamilton et al., 2016; Niklas \& Schneider, 2013; Skwarchuk, Sowinski, \& LeFevre, 2014; Torppa et al., 2007). We used a Confirmatory Factor Analysis in Mplus (Muthén \& Muthén, 2017) to test a second-order three-factor model that describes the HLE as a (general) factor in which three subfactors are included as the following:

1. Access to print was assessed with the following items: (a) How many children's books do you have at home? (1-5 (None to More than 40 books)). (b) How often do you visit a library with the child? (1-5 (Never to Several times a week)).

2. Literacy-related activities included the four following questions: (a) How often do you read to the child? (b) How often does the child watch TV? (c) How often does the child play TV/computer/tablet/mobile games? [1-5 (Never to Several times a week)]. (d) How old was the child when you first started reading to her or him? [1-5 (Never read to the child to before the age of 2)].

3. Parents' reading interest and habits were assessed by questions regarding how often they read (a) books, and (b) magazines for themselves [1-5 (Never to Several times a week)]. (c) Parents' own reading interest were assessed by the item 'I only read if I have to' [1-4 (Completely disagree to completely agree)]. 
The results of the Confirmatory Factor Analysis showed this second-order three-factor model had an adequate fit to the data: X2 $(17)=22.15, p=.18$; root mean square error of approximation $(\mathrm{RMSEA})=.04$, comparative fit index $(\mathrm{CFI})=.95$, and Tucker-Lewis index $(\mathrm{TLI})=.92$. The indicators were significantly related to the construct of HLE including access to print (factor loading =.43), literacy-related activities (factor loading $=.48$ ) and parents' reading interest and habits (factor loading $=.52$ ). A factor score with this HLE model was obtained and saved in Mplus for further analysis.

\section{Identifying RD at the end of Grade 2}

Towards the end of second-grade, a group of trained testers administered a large battery of tests. This study used four of these measures as a screening test to identify students with $\mathrm{RD}$, defined as performing below the 20th percentile in at least three out of the four word reading and spelling outcomes.

Word reading 1 consisted of 14 items, and the time limit was 2 min. For each item, a picture was represented along with four orthographically similar words, one of which corresponded to the picture. The child was asked to read all the words as fast as possible and to tick the word that matched the picture. For example, a picture of a wasp ('veps' in Norwegian) followed by 'vest', 'visp', 'veps', and 'vips'. After 2 min, the test was suspended and the number of correct answers was obtained. The maximum score was 14. Cronbach's $\alpha=.74$.

Word reading 2 (word chains test) included 78 sets of four words joined together. Students were required to insert a vertical line after each word that they identified, in order to separate each word from the next. One point was given if all four words were correctly identified by placing three lines correctly in a set of four words "herelmustlweeklsaid" ("herlmålukelsa" in Norwegian). Students were provided with three practice sets of word chains. For the task proper, students worked independently with a time limit of $5 \mathrm{~min}$. The score was the number of correct sets where all four words were identified. The maximum score was 78 (Cronbach's $\alpha=.84$ ).

Spelling 1 involved of 14 words with a variety of phonemes and phoneme sequences. The target word was first introduced in a short sentence to the child; then the target word was repeated for the child to write it down (e.g. "Father has a blue hat. Writel hat/"). The number of correctly spelled words was measured, and the maximum score was 14. Cronbach's $\alpha=0.84$.

Spelling 2 consisted of 14 words with a variety of phonemes and phoneme sequences. The target word was introduced in a short sentence and then the target word was repeated for the child to write it down. The instructions were the same as spelling 1. The maximum score was 14 , Cronbach's $\alpha=.74$.

\section{Statistical analyses}

Data were examined for missing data, outliers, skewness, and kurtosis. Values for both skewness and kurtosis in all variables were between \pm 2 , and there were no missing values. For the two first sets of analyses, presented in Tables 1 and 2, we 
used raw data except for the HLE and children's interest in literacy, for which factor scores were used. For the main set of logistic regression analyses, we also used factor scores for phoneme awareness based on the items from phoneme isolation and blending (see the method section).

\section{A multifactorial model of RD}

In Mplus, we used logistic regression analyses with maximum likelihood estimation. This enabled us to estimate simultaneously the associations among all variables in each model to predict children's RD (Muthén \& Muthén, 2017). Bootstrapping was used to examine indirect associations. We tested a multifactorial model of RD, built in two steps, based on the existing literature and previous research. These two steps are shown in Figs. 1 and 2 and discussed below. Gender, years in kindergarten and children's interest in literacy were also included in this model as background control variables to predict children's RD.

First, it was expected that parents' educational level would be associated with the HLE at the onset of reading instruction, and their RD status at the end of Grade 2. In addition, the HLE would predict children's RD indirectly via emergent literacy skills (Frijters et al., 2000; Sénéchal, 2006; van Bergen et al., 2017). This model is our first step in logistic regression analysis in Mplus and has been depicted in Fig. 1.

Based on earlier research, it was also hypothesized that FR would be associated with children's emergent literacy (Snowling \& Melby-Lervåg, 2016), parents' educational level and the HLE (Esmaeeli et al., 2018; Hamilton et al., 2016). In the second step, FR was added to the first model as both a direct predictor, and an indirect predictor of children's RD via the HLE and emergent literacy (Fig. 2).

\section{Results}

\section{Descriptive statistics and group differences}

Children falling below the cut-off points (set at the bottom $20 \%$ of the sample) in at least three out of the four measures of word reading (2 tests) and spelling (2 tests) at the end of Grade 2 were classified as having RD. In total, twenty-five children (12\%) were identified with RD at the end of Grade 2: 12 children in the Not-FR group and 13 children in the FR group. Children who did not meet this criterion were categorized as typical readers (TR): 147 children in the Not-FR group and 36 children in FR group. As expected, a significantly higher proportion of FR children $(26.5 \%)$ were identified as having RD than Not-FR children $(7.5 \%)$ at the end of second grade: $\left[X^{2}(1)=12.76, p<.001\right]$.

Table 1 presents the children's characteristics by group, and reports group differences between measures in the study. A series of two-way ANOVAs followed by Bonferroni tests (to adjust for multiple comparisons and reduce type I error) were run to investigate group differences (Tabachnick \& Fidell, 2007). There were no 


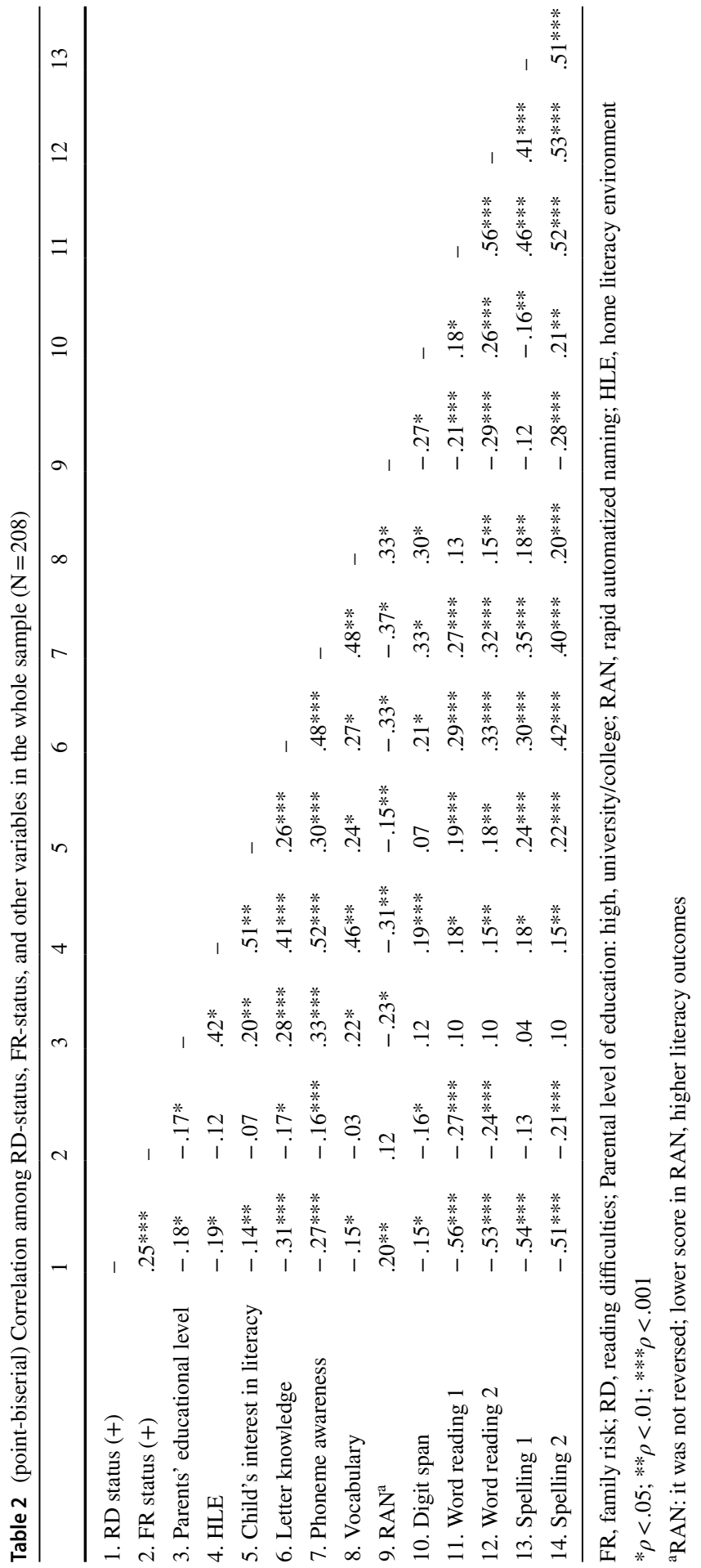




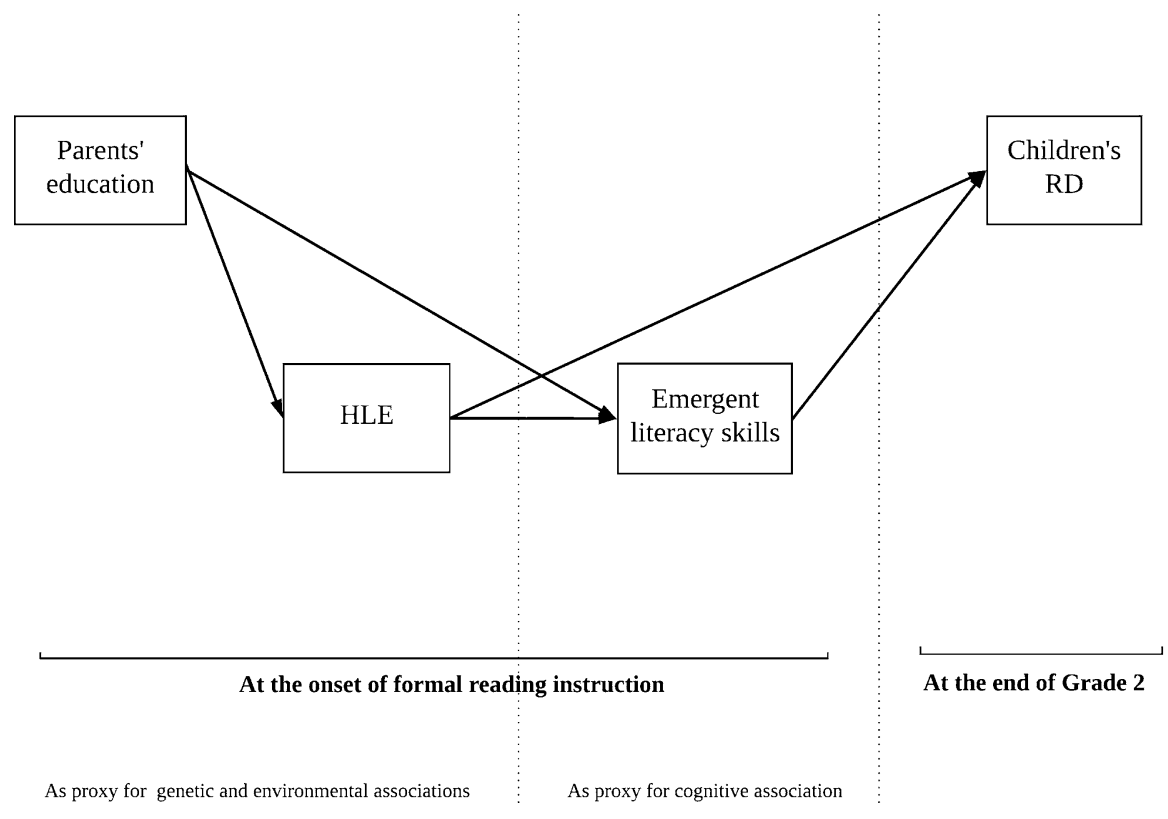

Fig. 1 A multifactorial prediction model of RD that includes the association between emergent literacy and the HLE. RD reading difficulties, HLE home literacy environment

group differences in years in kindergarten and average age in any subgroups of the present study.

\section{Parents' educational level and the HLE at the onset of formal reading instruction}

In the group of Not-FR children, for whom neither parent self-reported RD, parents' educational level $(d=.82)$ and the HLE $(d=.31)$ differed between TR children and RD children. However, in the group of FR children, parents' educational level and the HLE did not significantly differ between TR children and RD children.

In the group of typical readers, parents of Not-FR children reported higher educational levels $(d=.57)$, and scored better in the HLE $(d=.55)$ than parents of FR children. Whereas, in the group of RD children, no statistical differences were found either in parents' educational level or the HLE between Not-FR and FR children.

\section{Emergent literacy at the onset of formal reading instruction}

In the group of Not-FR children, TR children performed significantly better than RD children in letter knowledge $(d=.97)$, phoneme isolation $(d=.68)$, blending $(d=.85)$, RAN $(d=.78)$ and in their interest in literacy $(d=.21)$. However, there were no differences in their vocabulary or digit span outcomes. Among the FR group, TR children performed significantly better than RD children only in letter knowledge $(d=.78)$ and phoneme isolation $(d=.66)$ at the onset of formal reading instruction. 


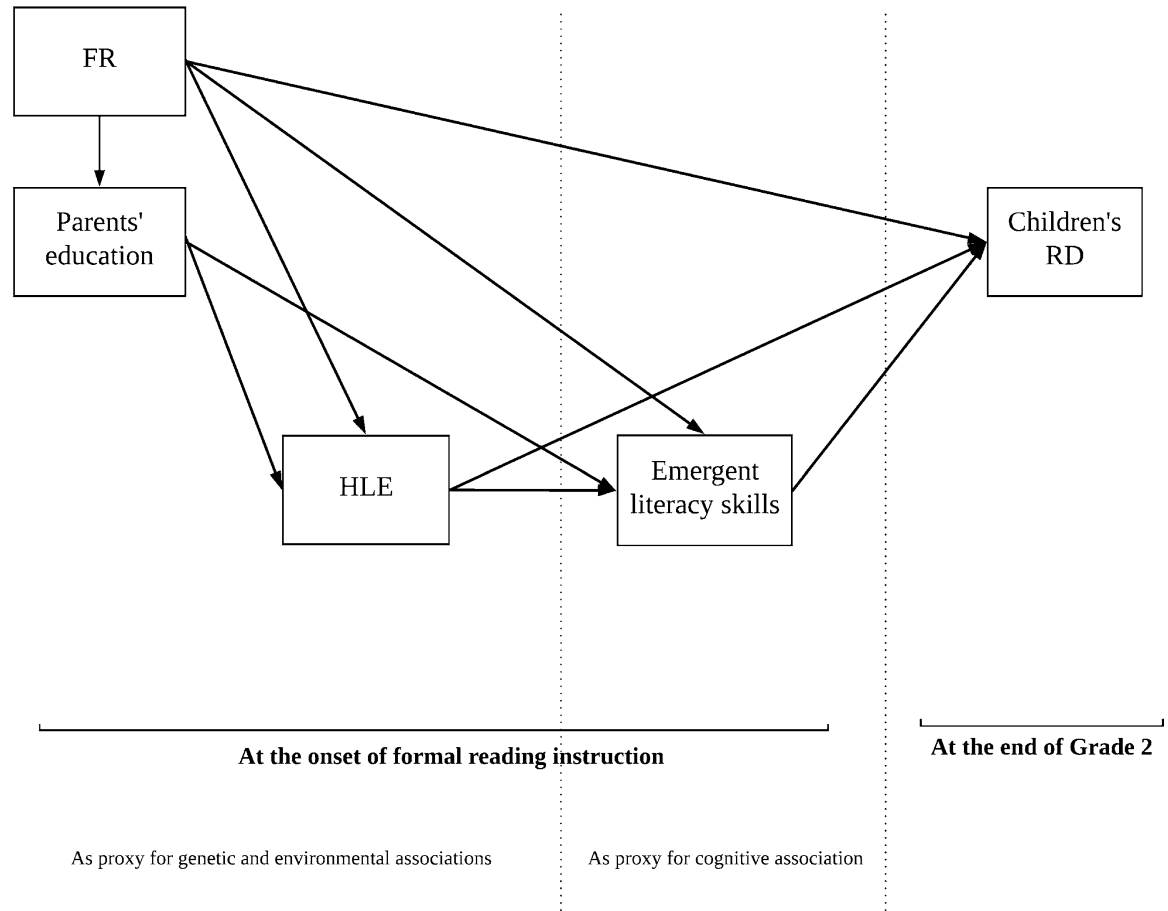

Fig. 2 A multifactorial prediction model of RD that includes the association between family risk, emergent literacy and the HLE. FR family risk, $R D$ reading difficulties, $H L E$ home literacy environment

In the group of typical readers, Not-FR children scored higher than FR children only on the blending task $(d=.39)$. This suggests that FR children, who were not identified as RD at the end of second-grade, showed some difficulties in emergent literacy at the onset of formal reading instruction.

In the group with RD, Not-FR children performed statistically at the same level as FR children in all emergent literacy, except for digit span $(d=.46)$.

\section{Literacy outcomes at the end of second-grade}

In the group of Not-FR children, TR children scored significantly higher than RD children on all measures of literacy at the end of second-grade. The same pattern has been shown in the group of FR children, where TR children performed significantly better than RD children. These results were expected and the effect sizes were large, because these measures of word reading and spelling were used to identify RD children.

In the group of typical readers, Not-FR children performed significantly better than FR children on both measures of word reading $1(d=.64)$ and word reading 2 $(d=.34)$, but not on either measure of spelling. These results suggest that FR children, who were not identified as RD at the end of second-grade, had nevertheless some reading problems. 
In the group of RD children, however, no statistical differences were found between those with a FR and those without.

\section{Correlation results}

Table 2 shows the point-biserial correlations of RD and FR status with the other measures in the study. Taking the sample as a whole, RD status was significantly, negatively correlated with all measures of emergent literacy at the onset of formal reading instruction, except for RAN, in which higher scores were positively associated with RD. RD was also negatively correlated with parents' educational level, the HLE and children's interest in literacy.

FR, as expected, was positively and significantly associated with RD. Significant negative correlations were found also between FR, letter knowledge, phoneme awareness, digit span, word reading 1, word reading 2 and spelling 2 . FR was not significantly related with either the HLE or children's interest in literacy.

\section{Logistic regression analysis}

The second and main aim of this study was to extend previous FR research by investigating whether FR remained a significant predictor of children's RD in a multifactorial model of RD that includes cognitive-based factors (emergent literacy) and environmental factors such as parents' educational level and the HLE.

To test our multifactorial prediction model, a two-step logistic regression analysis was constructed in Mplus using maximum likelihood estimator (ML).

Step 1 tested the association between parents' educational level, the HLE, and children's emergent literacy at onset of formal reading instruction, and children's $\mathrm{RD}$ at the end of Grade 2. Gender, years in kindergarten and children's interest in literacy were also included in this model as background control variables (Fig. 1).

As seen in Table 3, preschool letter knowledge (-.45), phoneme awareness $(-.57)$ and vocabulary $(-.24)$ were the only significant predictors of children's second-grade RD while accounting for, gender, years in kindergarten and children's interest in literacy. In this model, the HLE $(-.28, \rho \leq .06)$ was also marginally associated with children's second-grade RD.

Turning to indirect associations, two pathways of [Parents' education $\rightarrow$ HLE $\rightarrow$ Letter knowledge $\rightarrow$ RD: $(-.13), 95 \% \mathrm{CI}=[-.18,-.01], \mathrm{p}<.05]$, and [Parents' education $\rightarrow \mathrm{HLE} \rightarrow$ Phoneme awareness $\rightarrow \mathrm{RD}: \quad(-.18), \quad 95 \%$ $\mathrm{CI}=[-.26,-.01], \mathrm{p}<.01]$ remained significant after bootstrapping. The pathway of [Parents' education $\rightarrow$ HLE $\rightarrow$ vocabulary $\rightarrow$ RD: $(-.14), 95 \% \mathrm{CI}=[-.18,-.01]$, $\rho \leq .06)$ ] remained also marginally significant after bootstrapping.

In other words, the higher the initial levels of letter knowledge, phoneme awareness and vocabulary at the onset of formal reading instruction, the less likely the child would develop RD at the end of Grade 2. The amount of total explained variance $\left(R^{2}\right)$ in children's RD was $43.6 \%$ at Step 1 . 


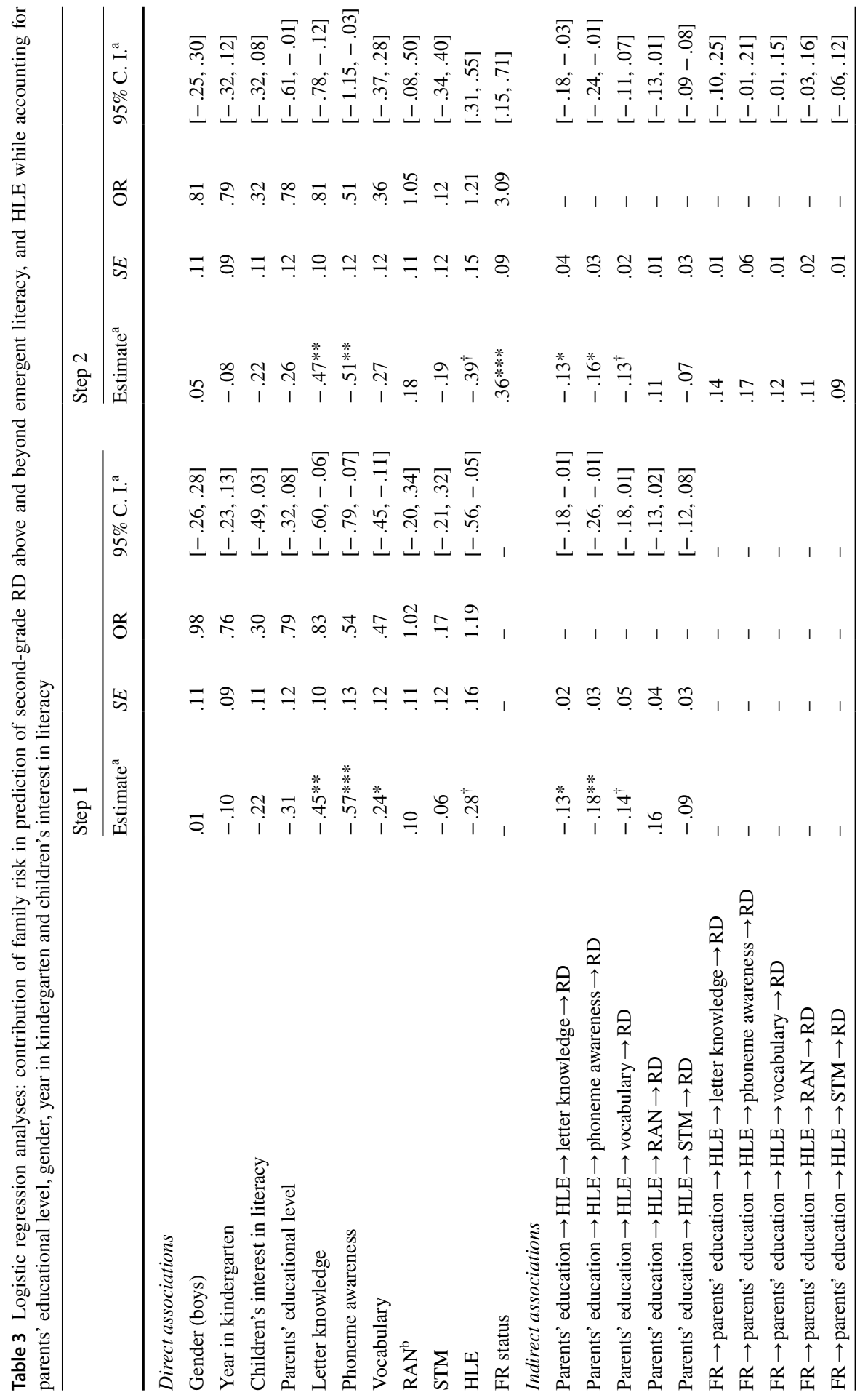




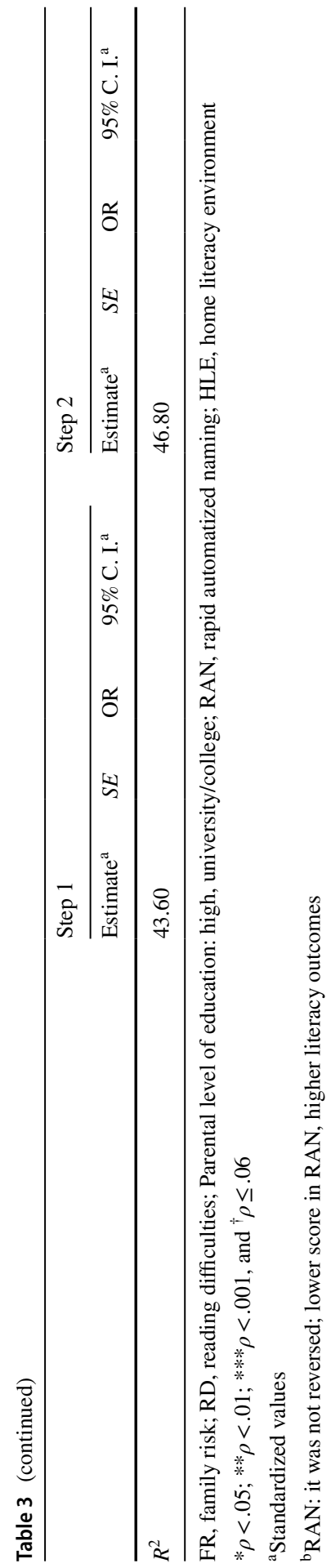


Step 2 tests whether FR predicts children's RD above and beyond emergent literacy, HLE, parents' education, gender, year in kindergarten and children's interest in literacy at the onset of formal reading instruction.

As depicted in Fig. 2, FR was entered at step 2 both as a direct predictor and as an indirect predictor via parents' education, the HLE and emergent literacy. As expected, family risk was directly associated with children's second-grade RD over and above parents' education, the HLE and emergent literacy skills while controlling for gender, years in kindergarten and children's interest in literacy (Table 3$)$. The amount of total explained variance $\left(R^{2}\right)$ in children's RD increased by $3.2 \%$ after adding FR as a direct and indirect predictors to the model. FR status provided a positive significant value $[\mathrm{FR} \rightarrow \mathrm{RD}:(.36), 95 \% \mathrm{CI}=[.15, .71]$, $\rho<.001]$. In addition, the odds ratio was 3.09 , suggesting that children with a positive FR status were three times as likely to develop RD, compared with children without FR in this multifactorial model of RD.

Interestingly, the significant association between preschool vocabulary scores and second-grade RD did not reach significance after adding FR status to the model in Step 2: $(-.27), 95 \% \mathrm{CI}=[-.37, .28], \rho \leq .06$.

Turning to indirect associations, two pathways of [Parents' education $\rightarrow$ HLE $\rightarrow$ Letter knowledge $\rightarrow$ RD: $(-.13), 95 \% \mathrm{CI}=[-.18,-.03], \rho<.05]$ and [Parents' education $\rightarrow$ HLE $\rightarrow$ Phoneme awareness $\rightarrow$ RD: $(-.16), \quad 95 \%$ $\mathrm{CI}=[-.24,-.01], \rho<.05]$ remained significant after bootstrapping, in Step 2. However, none of the indirect paths from FR status was found to be significant in this multifactorial model.

\section{Discussion}

The main aim of the current study was to predict children's later RD in a multifactorial model that included predictors across three different domains: FR, children's individual differences in emergent literacy at the onset of formal reading instruction, and environmental protective factors such as parents' educational level and the HLE.

Previous FR studies had shown that FR is a unique predictor of children's RD over and above emergent literacy (Puolakanaho et al., 2007), emergent literacy and oral language skills (Carroll et al., 2014), and children's general IQ, verbal IQ and emergent literacy in kindergarten, reading fluency and accuracy in Grade 2 and 3 (van Viersen et al., 2018). The novel findings from the current multifactorial prediction model extend the existing literature, indicating that FR predicts children's RD at the end of second-grade over and above cognitive factors (emergent literacy) and environmental factors (parents' education and HLE) while accounting for gender, children's interest in literacy and year in kindergarten. Our findings are in line with the multifactorial model of RD (Pennington, 2006; van Bergen et al., 2014), suggesting that RD is a set of complex difficulties that includes interaction of multiple risk and protective factors across three domains of cognitive-based, genetics and environmental factors. These findings will be discussed in more detail below. 


\section{Family risk and multifactorial model of RD}

In our multifactorial model of RD, family risk showed a direct, positive and significant association (.36) with RD over and above cognitive-based and environmental factors. This multifactorial model of RD suggests that FR is indeed a valuable proxy for genetic and environmental factors because even after accounting for environmental factors (parents' educational level and the HLE) and cognitive-based factors (emergent literacy), the direct and positive association between FR and children's RD remained significant.

A growing body of research (non-family risk studies), have used cognitive multivariate/multifactorial models to predict children's RD (Bishop \& League, 2006; Catts et al., 2017; McCardle et al., 2001; McGrath et al., 2011; Pennington et al., 2012). However, these studies did not include FR or environmental factors such as parents' education and the HLE. For example, Catts et al. (2017), in a multifactorial model including phonemic awareness, RAN and oral language, found that children with and without RD did not differ significantly in oral language, RAN or in the cooccurrence of deficits in these areas with phonological deficits.

This is the first study that empirically highlights the advantage of applying a multifactorial model of RD, in which the HLE could be explored as a potential protective environmental factor besides risk factors such as FR and emergent literacy difficulties. However, the HLE could be considered as a proxy for both environmental and genetic associations, since the HLE is correlated with parents' educational level. In our final prediction model, the associations between parents' educational level, the HLE, children's outcomes in some emergent literacy tasks and children's later RD were significant. This suggests reading difficulties are multidimensional and are best described in a multifactorial model. Snowling and Melby-Lervåg (2016) concluded that data on the HLE of FR children are scarce and suggested that an interaction of genetic and environmental risk and protective factors would determine where the skills of an individual would fall on the continuum of reading difficulties. The current study is a first step to address the interaction between risk and potential protective factors in the prediction of children's RD.

It is important to highlight that FR status in the current study is indexed by parents' self-report of RD only, which was based on two questions with self-reporting of RD from at least one parent. This simple but valuable self-report tool highlights the strength and importance of FR risk status, since parents' self-report of RD was associated with children's later literacy outcomes after 2 years of schooling, concurring with previous FR studies that either tested parents' literacy skills or used more comprehensive parents' self-reporting scales to identify FR children.

\section{Parents' self-report of RD, parents' educational level and the HLE at onset of formal reading instruction}

Interestingly, our data show that when parents report significantly higher levels of education, they also obtain significantly higher scores on the measure of HLE. Among the typical readers, parents of children without FR reported higher 
educational levels and achieved higher HLE scores than parents of children with FR. The same trend was also reported in the Not-FR group, where TR children's parents reported higher education levels and HLE than RD children's parents (Table 1). However, no significant differences in the HLE or parents' education were found either within the RD group (Not-FR vs. FR), or within the FR group (TR vs. RD). The current results suggest the important role of parental education in the association between FR status and the HLE. In other words, the FR status as a single factor is not sufficient by itself to examine differences in the HLE between the Not-FR group and the FR group and we should include parental educational level in this context (Esmaeeli et al., 2018; Hamilton et al., 2016).

\section{Parents' self-report of RD and emergent literacy at onset of formal reading instruction and literacy outcomes after 2 years of reading instruction}

Unsurprisingly, we found that FR children who went on to be categorised as having $\mathrm{RD}$ at the end of Grade 2 (FR-RD) had significantly poorer letter knowledge and phoneme isolation skills at school start than children who did not fulfil RD criteria (FR-TR). However, it is important to note that FR children who did not fulfil criteria for RD (FR-TR) at the end of Grade 2, had performed as poorly at the onset of formal reading instruction as FR-RD children in some measures of emergent literacy including blending, vocabulary, RAN and digit span. In addition, these FR-TR children performed significantly poorer than Not-FR-TR in both measures of word reading at the end of Grade 2. These findings, in line with previous FR studies, suggest that family risk is a continuous risk (Snowling, Gallagher, \& Frith, 2003; Snowling, Muter, \& Carroll, 2007), and may manifest differently over time. Our data suggest that FR children might show differential problems in different emergent literacy skills and in later literacy difficulties. This might explain why only some FR children may reach a threshold of impairment that is defined as RD (Snowling et al., 2003).

\section{Limitations and future research}

This study had several limitations that may direct future research. First, the parents' self-report that we used in this study as a proxy for FR was based on only two questions asking whether the mother or the father had experienced RD. Ideally, we would have used a parents' self-report measure based on a more comprehensive questionnaire (Leavett, Nash, \& Snowling, 2014; Lefly \& Pennington, 2000; Snowling et al., 2012), However, this simple but valuable self-report showed similar results in line with these previous FR studies. This suggests FR is such a strong risk factor that its effect on children's emergent literacy difficulties and later RD can be detected even by a simple parents' self-report. Parents' self-report of RD is indeed a valuable tool for screening FR children but it cannot, and should not, replace the use of more comprehensive identification tools for formal diagnosis of RD.

Second, the present study relied on parents' questionnaires to measure HLE, similar to the majority of previous research. Parents' questionnaires are an indirect 
measure which may be open to social desirability bias; although in the current study, the HLE correlated with children's outcomes on the concurrent measures of emergent literacy suggesting convergent validity. Given the potential disadvantage of questionnaires for parents with RD, we also tried to make our HLE questions as simple as possible with only multiple-choice answers.

Third, our multifactorial prediction model suggests the associations between FR, parents' education, HLE, and emergent literacy at school start, and children's RD at the end of second-grade is a complicated model. However, this study is a correlational study and therefore the causal mechanisms underlying children's RD should be interpreted with caution. Moreover, it remains to be determined in future research which kind of parent-child literacy-related activities might be more or less effective to help emergent literacy and later literacy development of FR children.

Finally, the current findings suggest a complex interaction between FR, HLE, children's emergent literacy at onset of formal reading instruction, and their later literacy outcomes. However, this study has not investigated the development of emergent literacy at different time points during the preschool years. Longer-term longitudinal studies are needed to clarify development of emergent literacy or later literacy skills in such a multifactorial model of RD.

\section{Implications and conclusion}

The current findings have practical implications for parents, teachers working with preschoolers and primary school students, and practitioners in the field of literacy difficulties. First, parents' self-report of RD can be a simple but valuable tool to screen at-risk children, although it is not sufficient to identify children with RD. Second, and most importantly, teachers and practitioners should be aware that the risk of developing later RD is almost three times higher for FR children with emergent literacy difficulties compared with Not-FR children with emergent literacy difficulties. Therefore, practitioners working with preschoolers and kindergarten children should monitor progress carefully when there is a self-report of RD for parents in addition to emergent literacy difficulties. Third, we cannot rule out the important role of preschool HLE although it was not a direct predictor of children's RD at the end of second grade.

In addition to practical implications, the current findings also have theoretical research-based implications. As suggested earlier in our multifactorial model, the preschool HLE may act as a potential environmental protective factor against possible risk factors such as FR and emergent literacy difficulties for the development of children's emergent literacy and later literacy skills. Hence, families, especially parents with RD or a history of RD, should be advised about the crucial role of emergent literacy and what they might be able to do to enhance or improve their children's emergent literacy in order to facilitate literacy development. Most parents, with and without RD, are able to provide support for the learning of letters and sounds prior to school via shared-reading activities in the home.

The majority of previous FR research included a direct measure of parents' literacy skills in addition to parents' self-report of $\mathrm{RD}$, partly because the validity and 
reliability of self-report of RD had not yet been documented. In addition, many of these studies had relatively small sample sizes, allowing for parents' literacy skills to be directly assessed. Nevertheless, the handful of studies that have used parents' self-report as a single measure to identify emergent literacy difficulties in FR children (Carroll \& Snowling, 2004; Esmaeeli et al., 2018) observed emergent literacy difficulties in FR children compatible with those from FR studies that used literacy tests in addition to parents' self-report of RD. Although the current study is a correlational study and therefore it cannot discuss the causal mechanisms underlying children's RD; our findings extend previous research by demonstrating substantial associations between parental self-report of RD and their children's emergent literacy before formal reading instruction and also with their literacy outcomes after 2 years of formal reading instruction. Consequently, researchers dealing with large scale studies could use this simple but valuable tool. Many previous FR studies had small sample sizes, possibly because of practical issues regarding with the administration of literacy tests to parents.

In conclusion, our data support the use of a multifactorial deficit model (Pennington, 2006; van Bergen et al., 2014) as a way of better understanding literacy difficulties. Our multifactorial prediction model for RD suggests that children whose parents' self-report RD, demonstrate reading difficulties that cannot be explained solely in terms of their individual differences in gender, interest in literacy, emergent literacy, or even differences in their immediate preschool environment such as the HLE, year in kindergarten and parental level of education. More importantly, we propose that although FR increases the likelihood of developing RD, the preschool HLE may operate as a potential protective environmental factor to enhance children's emergent literacy directly and their later literacy skills indirectly.

Acknowledgements This study is part of the 'On Track Project' that is supported by The Research Council of Norway, research programme 'FINNUT', Grant Number 237861. We would like to thank the principal investigators Oddny Judith Solheim and Per Henning Uppstad for their contribution to the project, and all affiliated research assistants, participating families and schools.

Open Access This article is distributed under the terms of the Creative Commons Attribution 4.0 International License (http://creativecommons.org/licenses/by/4.0/), which permits unrestricted use, distribution, and reproduction in any medium, provided you give appropriate credit to the original author(s) and the source, provide a link to the Creative Commons license, and indicate if changes were made.

\section{References}

American Psychiatric Association. (2013). Diagnostic and statistical manual of mental disorders (5th ed.). Washington, DC: Author.

Aro, T., Poikkeus, A. M., Eklund, K., Tolvanen, A., Laakso, M. L., Viholainen, H., et al. (2009). Effects of multidomain risk accumulation on cognitive, academic, and behavioural outcomes. Journal of Clinical Child \& Adolescent Psychology, 38(6), 883-898.

Bishop, A. G., \& League, M. B. (2006). Identifying a multivariate screening model to predict reading difficulties at the onset of kindergarten: A longitudinal analysis. Learning Disability Quarterly, 29(4), 235-252. 
Burgess, S. R., Hecht, S. A., \& Lonigan, C. J. (2002). Relations of the home literacy environment (HLE) to the development of reading-related abilities: A one-year longitudinal study. Reading Research Quarterly, 37(4), 408-426. https://doi.org/10.1598/RRQ.37.4.4.

Cardoso-Martins, C., \& Pennington, B. F. (2004). The relationship between phoneme awareness and rapid serial naming skills and literacy acquisition: The role of developmental period and reading ability. Scientific Studies of Reading, 8(1), 27-52.

Carroll, J. M., Mundy, I. R., \& Cunningham, A. J. (2014). The roles of family history of dyslexia, language, speech production and phonological processing in predicting literacy progress. Developmental Science, 17(5), 727-742. https://doi.org/10.1111/desc.12153.

Carroll, J. M., \& Snowling, M. J. (2004). Language and phonological skills in children at high risk of reading difficulties. Journal of Child Psychology and Psychiatry, 45(3), 631-640. https://doi.org/10. 1111/J.1469-7610.2004.00252.X.

Catts, H. W., McIlraith, A., Bridges, M. S., \& Nielsen, D. C. (2017). Viewing a phonological deficit within a multifactorial model of dyslexia. Reading and Writing, 30(3), 613-629. https://doi. org/10.1007/s11145-016-9692-2.

Catts, H. W., Nielsen, D. C., Bridges, M. S., Liu, Y. S., \& Bontempo, D. E. (2015). Early identification of reading disabilities within an RTI framework. Journal of Learning Disabilities, 48(3), 281-297.

Dilnot, J., Hamilton, L. G., Maughan, B., \& Snowling, M. J. (2017). Child and environmental risk factors predicting readiness for learning in children at high risk of dyslexia. Development and Psychopathology, 29(1), 235-244. https://doi.org/10.1017/S0954579416000134.

Elbro, C., Borstrom, I., \& Petersen, D. K. (1998). Predicting dyslexia from kindergarten: The importance of distinctness of phonological representations of lexical items. Reading Research Quarterly, 33(1), 36-60. https://doi.org/10.1598/Rrq.33.1.3.

Esmaeeli, Z., Lundetræ, K., \& Kyle, F. E. (2018). What can parents' self-report of reading difficulties tell us about their children's emergent literacy at school entry? Dyslexia, 24(1), 84-105. https://doi. org/10.1002/dys.1571.

Fletcher, J. M., Lyon, G. R., Fuchs, L. S., \& Barnes, M. A. (2007). Learning disabilities: From identification to intervention. New York: Guilford Press.

Frijters, J. C., Barron, R. W., \& Brunello, M. (2000). Direct and mediated influences of home literacy and literacy interest on prereaders' oral vocabulary and early written language skill. Journal of Educational Psychology, 92(3), 466. https://doi.org/10.1037/0022-0663.92.3.466.

Hamilton, L. G., Hayiou-Thomas, M. E., Hulme, C., \& Snowling, M. J. (2016). The home literacy environment as a predictor of the early literacy development of children at family-risk of dyslexia. Scientific Studies of Reading, 20(5), 401-419. https://doi.org/10.1080/10888438.2016.1213266.

Hulme, C., Nash, H. M., Gooch, D., Lervåg, A., \& Snowling, M. J. (2015). The foundations of literacy development in children at familial risk of dyslexia. Psychological Science, 26(12), 1877-1886. https://doi.org/10.1177/0956797615603702.

Hulme, C., \& Snowling, M. J. (2013). Developmental disorders of language learning and cognition. New York: Wiley.

Hume, L. E., Lonigan, C. J., \& McQueen, J. D. (2015). Children's literacy interest and its relation to parents' literacy-promoting practices. Journal of Research in Reading, 38(2), 172-193. https://doi.org/1 0.1111/j.1467-9817.2012.01548.x.

Leavett, R., Nash, H. M., \& Snowling, M. J. (2014). Am I dyslexic? Parental self-report of literacy difficulties. Dyslexia, 20(4), 297-304. https://doi.org/10.1002/dys.1481.

Lefly, D. L., \& Pennington, B. F. (2000). Reliability and validity of the adult reading history questionnaire. Journal of Learning Disabilities, 33(3), 286-296. https://doi.org/10.1177/002221940003300 306.

Lonigan, C. J., Schatschneider, C., \& Westberg, L. (2008). Impact of code-focused interventions on young children's early literacy skills. Developing early literacy: Report of the national early literacy panel (pp. 107-151).

Lovett, M. W., Frijters, J. C., Wolf, M., Steinbach, K. A., Sevcik, R. A., \& Morris, R. D. (2017). Early intervention for children at risk for reading disabilities: The impact of grade at intervention and individual differences on intervention outcomes. Journal of Educational Psychology. https://doi. org/10.1037/edu0000181.

Lundetræ, K., Solheim, O. J., Schwippert, K., \& Uppstad, P. H. (2017). Protocol: 'On Track', a grouprandomized controlled trial of an early reading intervention. International Journal of Educational Research. https://doi.org/10.1016/j.ijer.2017.08.011. 
McCardle, P., Scarborough, H. S., \& Catts, H. W. (2001). Predicting, explaining, and preventing children's reading difficulties. Learning Disabilities Research \& Practice, 16(4), 230-239. https://doi. org/10.1111/0938-8982.00023.

McGrath, L. M., Pennington, B. F., Shanahan, M. A., Santerre-Lemmon, L. E., Barnard, H. D., Willcutt, E. G., et al. (2011). A multiple deficit model of reading disability and attention-deficit/hyperactivity disorder: Searching for shared cognitive deficits. Journal of Child Psychology and Psychiatry, 52(5), 547-557.

Muthén, L. K., \& Muthén, B. O. (2017). Mplus user's guide (8th ed.). Los Angeles, CA: Muthén \& Muthén.

Niklas, F., \& Schneider, W. (2013). Home literacy environment and the beginning of reading and spelling. Contemporary Educational Psychology, 38(1), 40-50. https://doi.org/10.1016/j.cedps ych.2012.10.001.

Pennington, B. F. (2006). From single to multiple deficit models of developmental disorders. Cognition, 101(2), 385-413. https://doi.org/10.1016/j.cognition.2006.04.008.

Pennington, B. F., Cardoso-Martins, C., Green, P. A., \& Lefly, D. L. (2001). Comparing the phonological and double deficit hypotheses for developmental dyslexia. Reading and Writing, 14(7), 707-755.

Pennington, B. F., \& Lefly, D. L. (2001). Early reading development in children at family risk for dyslexia. Child Development, 72(3), 816-833. https://doi.org/10.1111/1467-8624.00317.

Pennington, B. F., Santerre-Lemmon, L., Rosenberg, J., MacDonald, B., Boada, R., Friend, A., et al. (2012). Individual prediction of dyslexia by single versus multiple deficit models. Journal of Abnormal Psychology, 121(1), 212-224. https://doi.org/10.1037/A0025823.

Puolakanaho, A., Ahonen, T., Aro, M., Eklund, K., Leppänen, P. H. T., Poikkeus, A. M., et al. (2007). Very early phonological and language skills: Estimating individual risk of reading disability. Journal of Child Psychology and Psychiatry, 48(9), 923-931. https://doi.org/10.111 1/j.1469-7610.2007.01763.x.

Sénéchal, M. (2006). Testing the home literacy model: Parent involvement in kindergarten is differentially related to grade 4 reading comprehension, fluency, spelling, and reading for pleasure. Scientific Studies of Reading, 10(1), 59-87. https://doi.org/10.1207/s1532799xssr1001_4.

Sénéchal, M., \& LeFevre, J.-A. (2002). Parental involvement in the development of children's reading skill: A five-year longitudinal study. Child Development, 73(2), 445-460. https://doi. org/10.1111/1467-8624.00417.

Skwarchuk, S. L., Sowinski, C., \& LeFevre, J. A. (2014). Formal and informal home learning activities in relation to children's early numeracy and literacy skills: The development of a home numeracy model. Journal of Experimental Child Psychology, 121, 63-84. https://doi.org/10.1016/J. Jecp.2013.11.006.

Snowling, M. J., Dawes, P., Nash, H. M., \& Hulme, C. (2012). Validity of a protocol for adult self-report of dyslexia and related difficulties. Dyslexia, 18(1), 1-15. https://doi.org/10.1002/dys.1432.

Snowling, M. J., Gallagher, A., \& Frith, U. (2003). Family risk of dyslexia is continuous: Individual differences in the precursors of reading skill. Child Development, 74(2), 358-373. https://doi. org/10.1111/1467-8624.7402003.

Snowling, M. J., \& Melby-Lervåg, M. (2016). Oral language deficits in familial dyslexia: A meta-analysis and review. Psychological Bulletin, 142(5), 498-545. https://doi.org/10.1037/bu10000037.

Snowling, M. J., Muter, V., \& Carroll, J. M. (2007). Children at family risk of dyslexia: A follow-up in early adolescence. Journal of Child Psycholgy and Psychiatry, 48(6), 609-618. https://doi.org/10.11 11/j.1469-7610.2006.01725.x.

Størksen, I., Ellingsen, I. T., Tvedt, M. S., \& Idsøe, E. M. (2013). Norsk vokabulartest (NVT) for barn i overgangen mellom barnehage og skole: Psykometrisk vurdering av en nettbrettbasert test [Norwegian Vocabulary Test (NVT) for children in transition between day care center and school. Reviewing psychometric properties of a computer tablet based test]. Spesialpedagogikks forskningsdel, 4(13), 40-54.

Tabachnick, B. G., \& Fidell, L. S. (2007). Using multivariate statistics. Boston, MA: Pearson Education.

Torgesen, J. K. (2002). Lessons learned from intervention research in reading: A way to go before we rest. In R. Stanthorp \& P. Tomlinson (Eds.), Learning and teaching reading (pp. 89-104). British Journal of Educational Psychology Monograph Series II, No. 1.

Torppa, M., Eklund, K., van Bergen, E., \& Lyytinen, H. (2011). Parental literacy predicts children's literacy: A longitudinal family-risk study. Dyslexia, 17(4), 339-355.

Torppa, M., Lyytinen, P., Erskine, J. M., Eklund, K., \& Lyytinen, H. (2010). Language development, literacy skills, and predictive connections to reading in Finnish children with and without familial 
risk for dyslexia. Journal of Learning Disabilities, 43(4), 308-321. https://doi.org/10.1177/00222 19410369096.

Torppa, M., Parrila, R., Niemi, P., Lerkkanen, M. K., Poikkeus, A. M., \& Nurmi, J. E. (2013). The double deficit hypothesis in the transparent Finnish orthography: A longitudinal study from kindergarten to grade 2. Reading and Writing, 26(8), 1353-1380.

Torppa, M., Poikkeus, A. M., Laakso, M. L., Eklund, K., \& Lyytinen, H. (2006). Predicting delayed letter knowledge development and its relation to Grade 1 reading achievement among children with and without familial risk for dyslexia. Developmental Psychology, 42(6), 1128-1142. https://doi. org/10.1037/0012-1649.42.6.1128.

Torppa, M., Poikkeus, A. M., Laakso, M. L., Tolvanen, A., Leskinen, E., Leppanen, P. H. T., et al. (2007). Modeling the early paths of phonological awareness and factors supporting its development in children with and without familial risk of dyslexia. Scientific Studies of Reading, 11(2), 73-103. https:// doi.org/10.1080/10888430709336554.

van Bergen, E., van der Leij, A., \& de Jong, P. F. (2014). The intergenerational multiple deficit model and the case of dyslexia. Frontiers in Human Neuroscience, 8, 346. https://doi.org/10.3389/fnhum .2014.00346.

van Bergen, E., van Zuijen, T., Bishop, D., \& de Jong, P. F. (2017). why are home literacy environment and children's reading skills associated? What parental skills reveal. Reading Research Quarterly, 52(2), 147-160.

van Viersen, S., de Bree, E. H., Zee, M., Maassen, B., van der Leij, A., \& de Jong, P. F. (2018). Pathways into literacy: The role of early oral language abilities and family risk for dyslexia. Psychological Science, 29(3), 418-428. https://doi.org/10.1177/0956797617736886.

Vellutino, F. R., Fletcher, J. M., Snowling, M. J., \& Scanlon, D. M. (2004). Specific reading disability (dyslexia): What have we learned in the past four decades? Journal of Child Psychology and Psychiatry, 45(1), 2-40. https://doi.org/10.1046/j.0021-9630.2003.00305.x.

Wechsler, D. (1991). WISC-III: Wechsler intelligence scale for children: Manual. San Antonio: Psychological Corporation.

Whitehurst, G. J., \& Lonigan, C. J. (2001). Emergent literacy: Development from prereaders to readers. In S. B. Neuman \& D. K. Dickinson (Eds.), Handbook of early literacy research (Vol. 1, pp. 11-29). New York, NY: The Guilford Press.

Publisher's Note Springer Nature remains neutral with regard to jurisdictional claims in published maps and institutional affiliations.

\section{Affiliations}

\section{Zahra Esmaeeli $^{1,2}$ (D) Fiona E. Kyle ${ }^{3}$ (Djersti Lundetræ ${ }^{1} \mathbb{D}$}

Fiona E. Kyle

fiona.kyle.1@city.ac.uk

Kjersti Lundetræ

kjersti.lundetre@uis.no

1 Norwegian Reading Centre, University of Stavanger, Professor Olav Hanssens vei 10, 4021 Stavanger, Norway

2 Department of Early Childhood Education, University of Stavanger, Stavanger, Norway

3 Division of Language and Communication Science, City University of London, London, UK 